\title{
DOCÊNCIA E DIFERENÇAS NAS ESCOLAS RURAIS: NARRATIVAS DE FORMAÇÃO NA PESQUISA (AUTO) BIOGRÁFICA
}

\author{
CHARLES MAYCON DE ALMEIDA MOTA \\ Secretaria Municipal de Educação de Várzea do Poço \\ JANE ADRIANA VASCONCELOS PACHECO RIOS \\ Universidade do Estado da Bahia
}

RESUMO Este artigo tem por objetivo compreender como os docentes das escolas rurais lidam com as diferenças em sala de aula, a partir das narrativas de formação de professores que atuam em classes multisseriadas. A metodologia para o desenvolvimento deste estudo utilizou princípios da pesquisa qualitativa, fundamentada na abordagem (auto)biográfica, tendo as narrativas como um dispositivo de investigação e utilizando-se da experiência como produtora de sentidos e significados sobre/da formação. A pesquisa foi desenvolvida com sete professores que atuam em classes multisseriadas de escolas rurais, no município de Várzea do Poço, interior da Bahia-Brasil, a partir da utilização de Oficinas Formativas, inspiradas nos Ateliês Biográficos, e do Memorial de Formação. Pudemos perceber, neste trabalho, que a diferença é concebida pelos docentes como um elemento de fronteira entre a aprendizagem e a situação social dos alunos de classes multisseriadas. Os docentes caracterizam a diferença, sobretudo a partir do lugar da dificuldade de aprendizagem, como atrelada aos elementos que normalizam e normatizam os sujeitos na escola, tratando-a, na maioria das vezes, como algo negativo no contexto da sala de aula.

Palavras-chave: Diferenças. Narrativas. Docência em classes multissseriadas.

\section{ABSTRACT TEACHING AND DIFERENCES IN RURAL SCHOOLS: NARRATIVES OF FORMATION IN AUTOBIOGRAPH RESEARCH}

This article aims to understand how the teachers of the rural schools deal with differences in the classroom, from the study on the narratives of teacher formation that work in multigrade classes. 
The methodology for the development of this study used principles of qualitative research, based on the (auto) biographical approach, with narratives as a research device and using experience as a producer of senses and meanings about/of formation. The research was developed with seven teachers who work in multigrade classes of rural schools, in the municipality of Várzea do Poço, in the interior of Bahia-Brazil, using Formative Workshops, inspired by Biographical Workshops and the Formation Memorial. We can perceive with this work that difference is conceived by teachers as an element of the boundary between learning and the social situation of students of multigrade classes. Teachers characterize the difference, especially regarding the difficulty of learning, as linked to the elements that normalizes and standardizes the subjects in the school, treating it, in most cases, as something negative in the context of the classroom.Keywords: Difference. Narratives. Teaching in classes multisseries. INVESTIGACIÓN (AUTO)BIOGRÁFICA

Este artículo tiene como objetivo comprender cómo los maestros de las escuelas rurales se ocupan de las diferencias en el aula, a partir del estudio de las narrativas de formación de maestros que operan en clases multiseriadas. Como enfoques metodológicos para el desarrollo de este estudio, hemos utilizado la investigación cualitativa, basada en el enfoque autobiográfico, tomando las narrativas como un dispositivo de investigación, utilizando la experiencia como productora de sentidos y significados de la formación. La investigación se realizó con siete maestros que trabajan en las clases multiseriadas en escuelas rurales, en el municipio Várzea do Poço, estado de Bahia, Brasil, a partir de la utilización de talleres formativos, inspirados por el Atelier biográfico, y del memorial de formación. Nos dimos cuenta con este trabajo de que la diferencia está diseñada por los profesores como un elemento de frontera entre el aprendizaje y la situación social de los estudiantes de las clases multiseriadas. Los maestros caracterizan la diferencia, especialmente, a partir del lugar de la dificultad de aprendizaje ligados a elementos que normalizan y estandarizan los sujetos en la escuela. Los maestros tratan la diferencia, en la mayoría de las veces, como algo negativo en el contexto del aula.

Palabras clave: Diferencias. Narrativas. Enseñanza en clases multiseriadas. 


\section{Introdução}

Cada vez mais, o cenário educacional tem se mostrado como um contexto de encontro cultural que forçosamente impulsiona professores e gestores a repensarem suas práticas, segundo outras perspectivas que possibilitem, não somente a validação do conhecimento científico, mas também a valorização de elementos intrínsecos às questões constituintes de concepções pautadas na diferença como responsáveis pela produção de nossas subjetivações e a construção-desconstrução-reconstrução de nossas identidades.

Neste sentido, identidade e diferença estão imbricadas, por manterem uma relação de interdependência, marcando e demarcando as condições de ser, pensar e existir dos sujeitos. A identidade e a diferença, ao longo dos tempos, foram tomadas a partir de uma suposição de pertencimento e não-pertencimento, sendo referenciado à identidade tudo aquilo que se colocava como bom, puro, divino, enquanto a diferença estava relacionada a tudo aquilo que se apresentava como impuro, ruim, inferior, negativo. Logo, "a identidade e a diferença se traduzem, assim, em declarações sobre quem pertence e sobre quem não pertence, sobre quem está incluído e quem está excluído. Afirmar a identidade significa demarcar fronteiras, significa fazer distinções entre o que fica dentro e o que fica fora" (SILVA, 2011, p. 82).

Pressupostos como estes apresentados desencadeavam condições de preconceito e estereótipos a grupos e sujeitos que não estavam incluídos, por apresentarem as marcas da diferença de maneira enfática e performática. Isso desencadeou diversas situações que provocaram rompimentos estruturais, a partir de movimentos e mobilizações de reivindicação da identidade, considerando fatores relacionados aos conflitos sociais intensificados na contemporaneidade; debates no cam- po das discussões pós-coloniais; superação da concepção de uma identidade una e fixa; fortalecimento de grupos constituídos pelas minorias políticas; rompimento das macroestruturas.

Neste sentido, as escolas rurais em suas especificidades se apresentam como um espaço em que se dá o encontro de culturas, em que as diferenças atravessam o cotidiano escolar, requerendo visibilidade e posicionamentos, sobretudo da docência, voltados para a realidade local e os saberes inerentes aos espaços rurais, como forma impulsionadora de aprendizagens. Ao tratarmos, especificamente, das classes multisseriadas, que são constitutivamente produzidas a partir da heterogeneidade dos sujeitos e das histórias de vida de cada um, dos seus ritmos, a diferença torna-se elemento fundante para o trabalho docente nas escolas.

Dessa forma, este estudo procura compreender como os professores lidam com a diferença nas classes multisseriadas, a partir de suas narrativas de formação. A pesquisa foi realizada em escolas rurais do município de Várzea do Poço, interior da Bahia, com a participação de sete professores-colaboradores ${ }^{1}$ que atuam em classes multisseriadas. 0 trabaIho resulta de uma experiência formativa, vivenciada no desenvolvimento de uma pesquisa-formação, com a colaboração de um grupo de professores de escola rural, que, tomando como elemento fundante seus percursos de vida-formação-profissão, compartilharam seus saberes e fazeres docentes, refletindo, revendo e discutindo o contexto das diferenças, em sala de aula.

As narrativas (auto)biográficas apresentam-se como um instrumento potente dessa

1 Os professores-colaboradores da pesquisa possuem nomes fictícios, em atendimento ao Comitê de Ética em Pesquisa da Universidade do Estado da Bahia UNEB, ao qual a pesquisa realizada foi submetida e aprovada através do Parecer no 1.231.903. 
perspectiva formativa, por enfatizarem os processos educacionais a partir de uma ótica que valoriza os sujeitos, as suas condições de vida e como produzem a docência nos espaços rurais, buscando a compreensão de uma multidimensionalidade que abarca o seu ser-fazer e thes possibilita a projeção de si, reorientando-os a um (re)posicionamento, a partir das perspectivas de futuro que tais sujeitos têm e que, no decorrer desse movimento da formação, são revistas, repensadas, reavaliadas, reconsideradas.

Com isto, buscamos as narrativas como uma proposta de formação centrada no sujeito e nas produções de sentido que este desenvolve em suas ações, de modo que tais narrativas se tornam a condição da reflexividade formativa, desencadeando, por isso mesmo, um processo de formação, autoformação e ecoformação (PINEAU, 2014).

O texto foi dividido em dois momentos nos quais abordamos, inicialmente, as bases e procedimentos da pesquisa-formação e, depois, as experiências trazidas pelos docentes, no trabalho com as diferenças na escola, a partir dos diálogos teóricos e das produções de sentido construídas nas narrativas de formação.

\section{Pesquisa-formação}

A produção deste trabalho se concentrou na realização de uma pesquisa-formação por compreender que os envolvidos pudessem refletir sobre suas práticas, a partir de suas experiências de vida, como subsídio para a aproximação de dimensões pessoais e profissionais, que não se dissociam, e emergem em todos os momentos, no cotidiano do fazer pedagógico. Entendemos que o foco epistemológico desta pesquisa se fundamenta nos princípios da pesquisa qualitativa, em que a subjetividade e os sentidos sobre o vivido são elementos que transversalizam a investigação.
A pesquisa-formação ressurge, a partir do movimento biográfico, com base nas discussões de Pineau (2006), entre os anos de 1983 a 1985, como uma proposta metodológica que enfatiza o compromisso do pesquisador com sua prática, focalizando uma mudança individual e coletiva, em que há uma corresponsabilidade entre o pesquisador e os colaboradores da pesquisa, no desenvolvimento da investigação, de maneira equivalente. Assim, cabe compreender que o desvelamento da pesquisaformação está atrelado à autonomia docente, pois demanda um conhecimento de si, a partir de reflexões e compreensões feitas diante das trajetórias de formação. Josso (2010) afirma que a pesquisa-formação tem sua legitimidade e a produção do saber pautadas na experiência que enfoca a coletividade, gerando todo um processo de intersubjetividade dos envolvidos.

O conhecimento construído na perspectiva da pesquisa-formação dá-se a partir de um processo de formação simultânea do pesquisador e dos colaboradores da pesquisa, desdobrado da situação de retroalimentação em que o formar e o formar-se acontecem, a partir das inter-relações presentes em uma estrutura dinâmica. A pesquisa-formação busca concentrar esforços no processo de reflexão a respeito das experiências de vida, evocando pontos que são primordiais ao conhecimento de si, ocorrendo, assim, um processo de formação que toma como base o individual e o coletivo, ambos transversais à vida de cada docente. Souza et al (2012, p. 140) enfatiza que:

O sentido e a pertinência do trabalho centrado na abordagem biográfica e de seu enquadramento como uma prática de investigação formação justifica-se porque não cabe uma teorização a posteriori sobre a prática, mas sim uma constante vinculação dialética entre as dimensões prática e teórica, as quais são expressas através da metarreflexão do ato de narrar-se, dizer-se de si para si mesmo como uma evoca- 
ção dos conhecimentos das experiências construídas pelos sujeitos.

Nesse âmbito, a pesquisa-formação ancora-se na produção de sentido e significado que dá suporte à construção coletiva dos grupos, em que a experiência apresentada pelos sujeitos, nesses grupos, desencadeia a construção de um conhecimento produzido coletivamente, legitimado e validado como um pressuposto de sua formação. Considerando tais fatores, podemos mencionar que a autonomia docente vai sendo construída paralelamente a esse movimento que transversaliza a vida desses docentes, oferecendo uma gama diversificada de possibilidades para o trabalho em sala de aula. Neste sentido, a pesquisa-formação é articulada ao método (auto)biográfico e traz como objetivo o conhecer a si através de um processo de reflexão que desemboca na tomada de consciência de si, podendo mobilizar os elementos necessários à sua própria formação. Isso faz com que os docentes superem a condição de meros reprodutores de saber, aplicando-se à produção do mesmo. Dominicé (2014, p. 81) afirma que:

[...] o estudo biográfico, apela à reflexão e resulta de uma tomada de consciência, dá origem a um material de investigação que é já o resultado de uma análise. A diversidade dos dados deve assim ser recebida como uma pluralidade de compreensão biográfica. 0 objetivo teórico da investigação ou a busca de uma teoria da formação tornam-se, então, indissociáveis de um aprofundamento da análise que cada um pode fazer sobre a sua formação.

O processo que se encontra envolvido no desenvolvimento da pesquisa-formação compreende a legitimidade do conhecimento de si, fazendo com que o docente possa definir e entender, através do decurso da própria vida, que a aprendizagem, nos procedimentos de formação sustentados pelas experiências de vida e profissão, desencadeia a teorização ne- cessária, decorrente desse percurso formativo, fincado no trabalho com o método (auto)biográfico, pois este exige um rigor que favorece a contemplação das subjetividades através de pré-requisitos compreensivo-interpretativos, possibilitando aos sujeitos em processo uma nova perspectiva sobre o seu fazer-se docente. Com isso, tais processos e procedimentos, que se encontram no cerne da pesquisa-formação, coadunam-se ao princípio de que se faz necessária a colaboração daqueles que narram suas histórias de vida, compreendendo-se como sujeitos de mudança que intervêm nas realidades vividas, ou seja, como construtores de sua autonomia profissional, partindo da diferença e das subjetividades.

No caso específico deste trabalho, a pesquisa-formação foi organizada a partir de Oficinas Formativas que foram construídas segundo a proposta dos Ateliês Biográficos apresentada por Delory-Momberger (2006, p. 366), reiterando que "o objetivo do ateliê é precisamente dar corpo a essa dinâmica intencional, reconstruindo uma história projetiva do sujeito e extraindo a partir dela projetos submetidos ao critério de exequibilidade".

As oficinas foram organizadas em nove encontros e divididas em três blocos temáticos, perfazendo um total de 30 horas de formação. 0 percurso de cada etapa foi planejado com vistas à promoção de espaços de formação, percebendo como os professores concebem a diferença na sala de aula, enfatizando que a realização dessas etapas culminaria na produção da memória formativa, que também se caracterizou como um dispositivo de pesquisa. As Oficinas Formativas foram realizadas com docentes das três escolas rurais do município e aconteceram quinzenalmente, na sede do município, nos horários de Atividade Complementar dos professores.

Neste caso, as narrativas possibilitam compreender os sentidos do fazer docente nas es- 
colas rurais, colocando-se como condições outras de formação que consideram os processos de nossa existência. Com isso, as formas de conhecimento (re)construídas são válidas e compõem o movimento de formação e autoformação docente. Diante dessas considerações, os professores-colaboradores da pesquisa foram motivados a narrar acerca de suas práticas docentes, apresentando suas aulas e outras atividades desenvolvidas nas classes multisseriadas, enfatizando o que consideravam como um fator primordial para o desenvolvimento do processo de ensino-aprendizagem, no contexto da sala de aula, e, sobretudo, como lidavam com as diferenças.

A pesquisa-formação considerou, no decorrer deste movimento formativo, o conhecimento de si como uma perspectiva formativa de oportunidade de tomada de consciência de si e como espaço de formação pensado como pressuposto de engajamento do docente no seu próprio processo de formação. Nesta lógica, o conhecimento de si cria condições para que o sujeito mobilize mecanismos inerentes ao processo de interiorização/exteriorização, por requerer um movimento bidimensional, que focaliza um aspecto das vivências individuais, condicionado aos processos de subjetivação, e outro aspecto das vivências coletivas, condicionado pelos processos de intersubjetividade.

Diante disso, podemos reiterar que a pesquisa-formação mobilizou o conhecimento de si como elemento fundante para pensar a docência nas escolas rurais. Neste sentido, os professores trouxeram várias dimensões acerca de suas práticas pedagógicas, sendo uma delas as bases teóricas e metodológicas que fundamentam o seu fazer. Colocar em questão o lugar de onde os professores falam trouxe à tona experiências de si, experiências do outro e experiências com o meio rural, que foram entrecruzadas à constituição da docência em classes multisseriadas.

\section{Territórios² da diferença na docência em escolas rurais}

Ao lidar com as emergências e significar as diferenças, a escola entra num território de embate entre as forças instituídas, as forças instituintes e os movimentos de resistência. Isto a coloca em contato com a grande tensão epistemológica que tem marcado a produção do conhecimento, nas últimas décadas. Uma abordagem da diferença, na perspectiva das singularidades/coletividades dos sujeitos, como uma dimensão que se constrói a partir do processo de produção de suas próprias subjetividades e de composição de suas identidades, faz-se presente na obra de Derrida (1986), quando lança mão do termo "différance", como forma de repensar os sentidos da palavra diferir, verbo transitivo direto que indica transferir, adiar; a este verbo são atribuídos, também, os sentidos de ser diferente, distinguir-se.

No que se refere à Educação, temos compreendido as diferenças como realidades sociohistóricas, em processo de construçãodesconstrução-construção, sendo estas constitutivas do sujeito, tornando-se um elemento intrínseco da prática pedagógica (CANDAU, 2011). Os estudos acerca das diferenças culturais presentes na escola têm nos apontado para duas abordagens distintas presentes na sala de aula: 1) a diferença como algo a ser extinto em nome da normalização e segregação dos sujeitos; e 2) a diferença como algo a ser assimilado a uma homogeneização, em nome de uma suposta igualdade.

Mesmo diante de tantos debates e de vasta produção teórica, ainda são muitas as tentativas de impor às diferenças que singularizam

2 Aqui, a ideia de território parte da premissa de uma produção que se desdobra "ao longo de um continuum que vai da dominação político-econômica mais 'concreta' e 'funcional' à apropriação mais subjetiva e/ou 'cultural-simbólica'”. (HAESBAERT, 2004, p. 95-96) 
os sujeitos algo relacionado à inferioridade ou à individuação. Quando a diferença é tomada pelo seu aspecto segregador, criam-se os paradoxos e as disjunções que ressaltam as relações de poder, as posições ambivalentes e conflituosas existentes. Assim, oposições como erudito e popular, rural e urbano, saber e ignorância são resultantes dessa perspectiva distintiva de perceber as diferenças. Neste caso, igualdade e diferença são vistas como dimensões contrapostas. Por outro lado, as diferenças percebidas pelo viés constitutivo, apontam para a necessidade de se atender ao diferente, em sua diferença, sem discriminá-lo ou inferiorizá-lo.

No caso específico deste estudo, ao lidar com a docência em classes multisseriadas de escolas rurais já partimos de construções sobre a diferença que dicotomizam a relação rural-urbano, uma vez que as escolas rurais sempre foram vistas como inferiores e sem qualidade, estando fadadas ao fracasso, pois a elas estava relegada uma política da falta. Isto se devia ao fato de conceber os espaços rurais, durante muito tempo, como apenas um lugar de produção agrícola e de extração de matéria-prima, desconsiderando os sentidos, as tradições e os processos de produção cultural existentes nestes locais. Através de lutas e embates construídos a partir século $X X, a$ educação oferecida em territórios rurais ocupa outros espaços de reconhecimento e de afirmação.

É neste cenário de (re)pensar o lugar das diferenças nas escolas rurais que esta pesquisa-formação foi realizada, compreendendo a necessidade de rompimento das fronteiras existentes nos espaços escolares, e considerando a riqueza do encontro de culturas que acontece na escola. Para isto, foram consideradas, como pressupostos norteadores, as narrativas de formação construídas no cotidiano da docência exercida em classes multisseria- das, em uma produção de sentidos acerca das experiências de si, das experiências do outro e das experiências com o meio rural. 0 trabatho com as narrativas (auto)biográficas nos possibilitou pensar que os fatos vividos pelos professores das escolas rurais tomam dimensionalidades distintas entre si, pois o que os diferencia são exatamente suas experiências construídas na cotidianidade de sua profissão. Estes professores, como sujeitos relacionais e com subjetividades próprias, constroem diferentes identidades, agem e reagem de diferentes maneiras em situações de vida-formação -profissão.

As nossas experiências nos constituem como seres da diferença que, por sua vez, nos tornam sujeitos singulares e da individuação, com particularidades específicas, contudo, sujeitos da coletividade e da pluralidade. Isso nos possibilita viver processos e situações de maneira peculiar, contribuindo para a construção de saberes diferentes e, portanto, experiências singulares. As diferenças nos dão condições para a convivência com nossos conflitos mais internos e o movimento de alteridade requer uma interação, o diálogo e a negociação necessários e importantes nas relações de confronto e nas tensões existentes entre eu, os outros e o ambiente que nos envolve.

As práticas pedagógicas dos professores de escolas rurais, colaboradores desta pesquisa, vão se desvelando de acordo com os diversos elementos que o contexto rural oferece. Elas são estruturadas a partir das concepções que estes docentes têm de educação, das identidades que construíram até o presente momento, dos pertencimentos e inter-relações que estabeleceram com seus pares e com a própria proposta de educação a ser oferecida nas escolas rurais. Diante disto, concebemos o espaço escolar como o território das diferenças, uma vez que é neste lugar que acontece 
o encontro das diversas culturas e que são produzidas as (não)condições de visibilidade, reconhecimento e valorização dos sujeitos, em suas dimensões que, em muitos momentos, foram marginalizadas, invisibilizadas e excluídas nas escolas. Candau (2011, p. 252) nos diz que:

A escola tem um papel importante na perspectiva de reconhecer, valorizar e empoderar sujeitos socioculturais subalternizados e negados. $\mathrm{E}$ esta tarefa passa por processos de diálogo entre diferentes conhecimentos e saberes, a utilização de pluralidade de linguagens, estratégias pedagógicas e recursos didáticos, a promoção de dispositivos de diferenciação pedagógica e o combate a toda forma de preconceito e discriminação no contexto escolar.

Para tanto, o desenvolvimento das práticas docentes dos professores-colaboradores toma como princípio as concepções de uma educação contextualizada, ${ }^{3}$ que possibilita a valorização da realidade e motiva os docentes e estudantes a construírem seus próprios conhecimentos, a partir da realidade dos territórios rurais. Clóvis, professor-colaborador, apresentou logo no início de sua narrativa de formação a importância do desenvolvimento do trabalho feito em classes multisseriadas, tendo como ponto de partida as concepções da educação contextualizada para o seu fazer docente.

[...] em relação ao trabalho com a diferença a gente tem procurado facilitar o nosso dia a dia com base nos próprios conhecimentos do aluno, a gente trabalha dentro do contexto, com aquela educação contextualizada. As atividades são programadas desde quando a gente prepara a ficha pedagógica, a gente aplica um diagnóstico, a partir do próprio conhecimento dos alunos, aí a gente resolve trabalhar com uma forma diferente, trabalhar com fichinhas de leitura, com letras, a própria sílaba, na formação de palavras, gravuras, colagem, pinturas, a

3 Proposta educacional adotada pelo município de Várzea do Poço/BA, baseada nas teorias de Paulo Freire para fundamentar a prática pedagógica dos docentes das escolas rurais. gente trabalha com historinhas infantis diante da ficha pedagógica e também a gente assiste diversos tipos de vídeo, com base no contexto. (Clóvis, Extrato da narrativa, 2016)

O que pudemos perceber na apresentação da proposta de educação contextualizada focalizada pelo docente, ao falar das diferenças que atravessam o cotidiano de sua sala de aula, é que há uma concepção de contextualização aqui que não se centra, especificamente, no sujeito, ou seja, não é uma educação que considere as diferenças do sujeito, mas que aponta para uma diferença de estratégias metodológicas. Variar a dimensão das atividades que se desenvolvem em sala de aula não garante uma educação contextualizada, uma vez que esta deveria partir da compreensão de que os sujeitos são diferentes e que por isso as ações pedagógicas deveriam ser pensadas a partir dessa condição/constituição dos alunos.

No que se refere à Proposta de Educação Contextualização apresentada para as escolas rurais, o contexto toma centralidade como “ponto de ancoragem dos processos pedagógicos, mas para fincar aí e a partir daí as condições da mudança com os outros das 'narrativas hegemônicas', cujas colorações são de caráter étnico, etário, de gênero, territorial, ambiental, ético, estético, etc." (MARTINS, 2009, p. 30-31). Nesta proposta, os docentes envolvidos devem considerar o conhecimento do estudante, numa tentativa de trazer à tona o lugar identitário do saber produzido no espaço rural, porém o que percebemos nas narrativas é que a identidade não foi fortalecida em sua construção no momento em que a diferença não é colocada numa posição ambivalente, em negociação e deslocamento. Entretanto, o que ficou em evidência nas narrativas de formação dos professores-colaboradores é a tradução da Proposta de Contextualização como uma prática diagnóstica das dificuldades de aprendizagem dos estudantes, sendo esta uma das 
visões fundantes do professor sobre a diferença nas classes multisseriadas. Como podemos observar na narrativa de Renato:

[...] Hoje, continuo lecionando com uma prática pedagógica completamente diferente daquela do passado, onde o professor transmitia conteúdos, sendo uma autoridade do saber. Hoje, eu tenho que descobrir o que os alunos já têm de conhecimento, ser um facilitador, um guia para um processo de transmissão de uma série de conhecimento, trabalhar com eles vários tipos de gêneros textuais, ciranda do baú, produção de texto, textos fatiados, textos com erros ortográficos, para fazer a correção, juntamente com eles, enfim, trabalhar a contextualização na sala de aula, para que eles alcancem várias técnicas e padrões, que tornam o indivíduo com várias habilidades na leitura, na escrita, na interpretação e discursos de textos, sempre usando técnicas onde os alunos podem participar com a interação em grupo. Quando meus alunos estão com dificuldade de aprendizagem, tenho que diagnosticar, com o intuito de buscar caminhos para a melhor aprendizagem. A contextualização ajuda neste aspecto. Sempre planejando as atividades, de acordo com as dificuldades dos alunos, onde eles possam participar da construção de seu próprio conhecimento, observando se eles estão sendo atingidos, e se estão conseguindo alcançar os objetivos. Fazer também com que eles reflitam sobre seus erros e acertos, usando sempre a comunicação, motivando para construir e reconstruir num processo pedagógico. (Renato, Extrato da narrativa, 2016)

Ao falar de si, Renato aponta um outro lugar da docência ocupado por ele, ao assumir classes multisseriadas. O docente reconhece-se neste espaço como um professor facilitador de aprendizagem. É neste sentido que contextualizar para ele significa reconhecer as dificuldades do outro (estudante de escolas rurais multisseriadas), para poder adaptá-lo e adequá-lo ao modelo. Neste aspecto, "o que se tornou Outro, estranho ou diferente na escola passa pela tradição que reifica o mesmo, expresso na padronização, nos modelos, na homogeneização construídos pela cultura da escola. Classificar, normalizar e segregar os sujeitos fazem parte de uma cultura institucional [...]" (RIOS, 2016, p. 290). Percebemos nas narrativas que o foco da proposta contextualizada se centra na ideia da diversidade de ritmos, modos de aprender e de características cognitivas e fisicas que singularizam e definem os indivíduos. Os diferentes modos de ser e (com) viver no espaço rural e suas sociabilidades são silenciados nas narrativas dos docentes, ao se referirem à Proposta da Educação Contextutalizada.

0 docente retoma aqui resquícios das vertentes da psicologia da aprendizagem e da escola nova, do início do século XX, em que a diferença era sinônima de deficiência de aprendizagem. Esta visão atravessou as narrativas dos docentes neste estudo. Em suas experiências formativas, os professores vão apresentando suas concepções sobre a diferença, caracterizando-a a partir do lugar da dificuldade de aprendizagem. Vale ressaltar que, quando os professores-colaboradores mencionam a percepção das aprendizagens que os alunos apresentam, a fazem de uma maneira que caracteriza o aluno de uma forma negativa, em que são observados apenas os aspectos que lhes faltam, não levando em consideração o que estes alunos são de fato. Assim, as diferenças culturais vão ficando despercebidas nos contextos da escola, deixando espaço para a perpetuação de ações carregadas de preconceito e estigmas sobre os estudantes de escolas rurais.

Com isso, as possibilidades de compreensão dos elementos que estão relacionados às dificuldades de aprendizagem dos estudantes se expandem e favorecem a busca de estratégias diversas, que colocam como mecanismos de aprendizagem, oferecendo a tais estudantes acolhimento e segurança, direcionando seus fazeres pedagógicos através de perspec- 
tivas que valorizem a superação da diferença. A narrativa de Rafaela apresenta esses aspectos.

[...] Olho para cada um, principalmente aquele com menos conhecimentos, com mais dificuldades na aprendizagem, o mais quieto... alguma coisa dentro deles(as) eu vejo. Tento descobrir o que eles(as) têm de melhor para, juntos, alcançarmos o objetivo que queremos alcançar. Reflito, com cuidado, o valor de cada um(a), a fim de que possa chegar à absoluta compreensão da importância e contribuição de cada um, na dedicação para o aprendizado. (Rafaela, Extrato da narrativa, 2016)

O cuidado com o outro apresenta-se no perfil profissional que Rafaela traça de si, tecendo a compreensão de que é fundamental olhar para as diferenças presentes em sala de aula, a partir da compreensão acerca da dificuldade que o estudante apresenta. A identidade e a diferença aparecem na narrativa da docente como fatos naturais, essencializados na vida social dos alunos. A diferença que precisa ser cuidada, resolvida, é concebida como "desvio", negativamente produzida no interior das relações desenvolvidas no espaço escolar, traduzidas na sua concepção binária (RIOS, 2011)

Ao conceber e ressaltar o lugar da diferença nas classes multisseriadas pela negatividade e pela falta produzida pela dificuldade de aprendizagem, surge outro elemento que a caracteriza, nesta perspectiva, que é a condição socioeconômica dos estudantes do meio rural. Marta apresenta em suas narrativas suas experiências construídas na relação com a diferença, traduzida em dificuldade de aprendizagem, com os estudantes de classes multisseriadas na relação com o contexto familiar/social de onde eles são provenientes:

Na sala de aula, todos os dias [...] aparece dificuldade, aparece aquele aluno que não tomou café que tem dificuldade de aprendizagem por isso, aparece aquele aluno que em casa o pai brigou, tem aquele que tem deficiência que quando tem um trabalho de grupo não quer ficar junto, tem aquele que tem dificuldade de aprendizagem, são diversos fatores que aparecem na sala de aula e, como professora, tenho que ter aquele discernimento de entender cada dificuldade de cada um e procurar trabalhar em cima daquela dificuldade de cada um pra que todos saiam ganhando. (Marta, Extrato da narrativa, 2016)

A docente enfatiza a diferença a partir da ausência de elementos intrínsecos à condição social e econômica em que seus alunos vivem, atrelando a tais condições as dificuldades de aprendizagem que surgem no contexto da sala de aula. Estas concepções vão sendo construídas, sorrateiramente, em que as diferenças vão sendo percebidas com maior ênfase em seus aspectos negativos. É importante mencionar que, ao relacionar as diferenças às condições socioeconômicas dos alunos, a professora compreende que a sala de aula está permeada por uma diversidade de fatores que exigem delas posicionamentos de respeito e acolhimento, buscando entender as situações de vida de seus alunos e suas possiveis dificuldades para estabelecer um trabalho que considere este contexto como um pressuposto para o desenvolvimento da aprendizagem.

Edson também apresenta as condições sociais e econômicas dos estudantes como marca da diferença presente nas classes multisseriadas,

[...] a questão da diferença que sempre o professor que está na sala de aula se depara [...], a gente encontra filho de pais que não tem aquele acompanhamento como deveria ter com os filhos, [...] a gente também encontra filhos que vem para a escola que não tem [...] uma boa alimentação em casa, a gente também percebe [...] a desestrutura de alguns pais na formação de seus filhos e aí a gente vê essas diferenças dentro da sala de aula pra poder a gente tentar lidar com essas diferenças, ou seja, a gente tem que estar sempre preparados pra poder a 
gente lidar com essas diferenças, [...] então a gente tem que ter uma atenção especial para essas crianças porque a criança não é a culpada do que está acontecendo, mas sim o convívio social e [...] muitas vezes também pelo poder aquisitivo [...]. (Edson, extrato da narrativa, 2016)

Esta visão do professor retoma a perspectiva da vertente sociológica ${ }^{4}$ do início do século XX sobre as diferenças presentes na educação construídas a partir da estratificação social. Podemos compreender que a concepção de diferença desse professor traz um sentido infimo por considerar as diferenças inerentes aos fatores socioeconômicos de seus alunos, ou seja, se não houvesse a classificação de tal fator não existiriam as diferenças. Isso desconsidera a importância das subjetividades no processo de produção das identidades, com tentativas de reservar para os alunos a mesmidade, como uma forma ingênua, mas com suas intencionalidades, de lidar com as relações nos espaços da sala de aula. Para Bhabha (2013), a diferença segue uma lógica da subversão, e considerá-la requer novas reformulações de conceitos e princípios, até então tidos como válidos e importantes, mas que, de acordo com a reconfiguração das estruturas sociais e políticas, na contemporaneidade, necessitamos lançar mão de concepções outras que levem em conta as produções decorrentes das convergências e divergências que acontecem no interior dos grupos e são elementos necessários à construção de nossas subjetivações, favorecendo a compreensão dos diferentes jeitos de ser, pensar, agir e viver.

O olhar sobre a diferença na busca por razões que caracterizam a dificuldade de aprendizagem dos estudantes de classe multisseriada ainda é uma constante nas narrativas de formação dos docentes. Os professores sinali-

4 Os estudos da Nova Sociologia da Educação, nos anos de 1960, foram fundamentais para discutir esta dimensão da diferença na Escola. zam o lugar da falta na produção da diferença no cotidiano das salas de aula. A diferença é construída na negatividade, sendo algo a ser superado, suprimido, homogeneizado. Assim, percebemos que a concepção dos professores das escolas rurais sobre as diferenças ainda se encontra ancorada na busca de tornar os sujeitos iguais, padronizados, em que as diferenças são mascaradas ou negadas, numa tentativa de fabricar uma identidade, o que caracteriza a produção da mesmidade, desconsiderando uma proposta que seria construída a partir da "[...] simultaneidade como possibilidade do tempo, em que a relação ética com o outro é condição para as práticas educativas. Vale ressaltar que essa relação ética com o outro pressupõe o seu reconhecimento, não como representação, mas como diferença" (PINHO, 2012, p. 140). Isso significa dizer que, quando as diferenças são tomadas por uma perspectiva de negação ou ocultamento, os ritmos de cada sujeito não são respeitados, pois o que está em voga é apenas um tempo imposto por aquele que não respeita a relação ética com o outro, como uma possibilidade de considerar a temporalidade do outro.

A escola como um território da diferença requer um fazer docente que dê centralidade às questões referentes à identidade e à diferença, como uma proposição de superação de posicionamentos fundamentados numa visão maniqueísta, trazendo possibilidades de construção-desconstrução-reconstrução das identidades, como uma forma de evitar alguns movimentos inspirados na sobreposição cultural que, na maioria das vezes, desconsideram os sujeitos, suas identidades e subjetividades, intensificando processos de exclusão e marginalização.

\section{Considerações finais}

O desenvolvimento deste trabalho nos proporcionou reflexões na busca da compreensão de 
como os professores das escolas rurais concebem a diferença em sala de aula através de suas práticas pedagógicas. Dessa maneira, esta pesquisa colaborou de maneira significativa para a construção de concepções outras sobre as fronteiras que (de)marcam as diferenças dos professores e alunos de classes multisseriadas, tomando como base uma perspectiva fundada no movimento de formação docente que abarca os pressupostos inerentes às necessidades dos professores-colaboradores e que fossem emergindo no desenvolvimento do processo de pesquisa-formação.

A diferença aparece na pesquisa com variados sentidos, ora como característica própria de cada sujeito, ora como um elemento que precisa ser mascarado, a partir das tentativas de homogeneizar os alunos. As diferenças vão sendo demarcadas, a partir das narrativas dos professores, especificamente pela dificuldade de aprendizagem que seus alunos apresentam e pelo fator socioeconômico. Neste sentido, fica evidente que a diferença é concebida pelos professores como elemento de fronteira entre a aprendizagem e a situação social dos alunos de classes multisseriadas. Assim, os professores caracterizam a diferença a partir do lugar da dificuldade da aprendizagem atrelada aos elementos que normalizam e normatizam os sujeitos na escola, tratando-a, na maioria das vezes, como algo negativo no contexto da sala de aula, atribuindo também à diferença um lugar das ausências.

\section{Referências}

BHABHA, Homi K. O local da cultura. 2. ed. Belo Horizonte: Editora UFMG, 2013.

CANDAU, Vera Maria Ferrão. Diferenças culturais, cotidiano escolar e práticas pedagógicas. Revista Currículo sem Fronteiras, v. 11, n. 2, p. 240-255, jul./ dez. 2011.

DELORY-MOMBERGER, Christine. Formação e socialização: os ateliês biográficos de projeto. Educação
0 que podemos afirmar que os docentes precisam compreender, no entrecruzamento das experiências de si, do outro e do meio rural, que os estudantes das escolas rurais multisseriadas são sujeitos produzidos pela identidade e pela diferença, sendo estas constitutivas dos modos de ser e (com)viver nos territórios rurais. Neste sentido, as práticas pedagógicas devem ser contextualizadas pela ancoragem nas diferenças culturais dos sujeitos e não fora dela, para que possam, assim, potencializar a produção de saberes e as diferentes práticas culturais que possam surgir nestes territórios das diferenças.

Considerar o fazer docente nas classes multisseriadas é atentar para todos esses elementos que tentam descaracterizar os sujeitos que vivem nas áreas rurais, oferecendo condições para que esses meninos e meninas possam se reconhecer enquanto protagonistas de suas próprias vidas. Os questionamentos, dilemas, desafios e inquietações que circundam o fazer docente no meio rural são inúmeros, ressurgindo a partir das narrativas dos professores-colaboradores que apontam para a necessidade do desenvolvimento de práticas pedagógicas que atendam as novas demandas que se materializam de acordo com as especificidades inerentes aos modos de vida, em que temos os sentidos, valores e princípios produzidos a partir das vivências em áreas rurais.

e Pesquisa, São Paulo, v. 32, n. 2, p. 359-371, mai./ ago. 2006.

DERRIDA, Jacques. A diferença. In: DERRIDA, Jacques. Margens da filosofia. Porto: RÉS Editora, 1986. p. 33-63.

DOMINICÉ, Pierre. O processo de formação e alguns dos seus componentes relacionais. In: FINGER, M.; NÓVOA, A. (Orgs.). 0 método (auto)biográfico e a 
formação. 2. ed. Natal: EDUFRN, 2014. p. 77-90.

HAESBAERT, R. 0 mito da desterritorialização: do "fim dos territórios" à multiterritorialidade. Rio de Janeiro: Bertrand, 2004.

JOSSO, Marie-Christine. Caminhar para si. Porto Alegre: EDIPUCRS, 2010.

MARTINS, Josemar da Silva. Contextualizando contexto. Caderno Multidisciplinar: Educação e contexto no semiárido brasileiro: Múltiplos espaços para o exercício da contextualização. Juazeiro: Selo Editorial RESAB, 2009.

PINEAU, Gaston. A autoformação no decurso da vida: entre a hetero e a autoformação. In: FINGER, M.; NÓVOA, A. (Orgs.). 0 método (auto)biográfico e a formação. 2. ed. Natal: EDUFRN, 2014. p. 91-110.

PINHO, Ana Sueli Teixeira de. 0 tempo escolar e o encontro com o outro: do ritmo à simultaneidade. 2012. 274 f. Tese (Doutorado em Educação) - Departamento de Educação, Universidade de Estado da Bahia, Salvador, 2012.
RIOS, Jane Adriana Vasconcelos Pacheco. Ser ou não ser da roça, eis a questão! Identidades e discursos na escola. Salvador: EDUFBA, 2011.

RIOS, Jane Adriana Vasconcelos Rios. Diversidade, direitos humanos e formação docente no cotidiano escolar da Educação Básica. In: CARVALHO, Maria Vilani Cosme de.; CARVALHÊDO, Josania Lima Portela; ARAUJO, Francisco Antonio Machado. Caminhos da Pós-Graduação em Educação no Nordeste do Brasil. (Orgs.). Teresina: EDUPI, 2016. p. 287-300.

SILVA, Tomaz Tadeu da. Identidade e diferença. A perspectiva dos Estudos Culturais. 10. ed. Petrópolis, RJ: Vozes, 2011.

SOUZA, Elizeu Clementino; PINHO, Ana Sueli Teixeira de; MEIRELES, Mariana Martins de. Tensões entre o local e o global: ruralidades contemporâneas e docência em escolas rurais. Revista Educação, Santa Maria, v. 37, p. 351-364, 2012.

Recebido em: 30/08/2016

Aprovado em: 21/03/2017

Charles Maycon de Almeida Mota é Mestre em Educação e Diversidade pelo Programa de Pós-Graduação em Educação e Diversidade da Universidade do Estado da Bahia, Departamento de Ciências Humanas, Campus IV, Jacobina. Professor da Educação Básica da Rede Pública Municipal de Várzea do Poço/Bahia; Membro do Grupo de Pesquisa Docência, Narrativas e Diversidade na Educação Básica - DIVERSO. e-mail: charlesmaycon22@hotmail.com

Rua Durval Gama, no 77, Centro. Várzea do Poço - Bahia - Brasil. CEP: 44.715.000. Fone: (74)99643152.

Jane Adriana Vasconcelos Pacheco Rios é Pós-doutora em Educação pela Universidade de São Paulo - USP. Doutora em Educação pela Universidade Federal da Bahia - UFBA. Professora Titular do Departamento de Educação da Universidade do Estado da Bahia (UNEB) - Campus I. Professora do Programa de Pós-Graduação em Educação e Contemporaneidade e do Programa de Pós-Graduação em Educação e Diversidade - UNEB; Líder do Grupo de Pesquisa Docência, Narrativas e Diversidade na Educação Básica - DIVERSO. e-mail: jhanrios1@yahoo.com.br

Avenida Cardeal da Silva, 523 - Ed. Liliana, apto 703 - Federação - Salvador-Bahia-Brasil CEP: 40.230 .305 Fone: (71) 99204-3623 